\title{
A simple HPLC-MS/MS method for the analysis of multi-mycotoxins in betel nut
}

\author{
Hung-Yu Lin ${ }^{1}$, Dinesh Chandra Agrawal ${ }^{1}$, Wen-Goang Yang ${ }^{2}$, Wei- \\ Jun Chien ${ }^{*}$ \\ ${ }^{1}$ Department of Applied Chemistry, Chaoyang University of Technology, Taichung, \\ Taiwan, R.O.C. \\ ${ }^{2}$ Department of Leisure Services Management, Chaoyang University of Technology, \\ Taichung, Taiwan, R.O.C.
}

\begin{abstract}
Mycotoxins are naturally occurring toxins produced by certain molds and can be found in nuts, cereals, fruits, and oils. Furthermore, current food processing systems cannot wholly remove mycotoxins. The adverse health effects of chewing betel nut containing mycotoxins range from long-term consequences such as immune deficiency. In this study, a rapid solid-phase extraction (SPE) method to LC-MS/MS system was developed to determine nine mycotoxins in commonly used five types of betel nut products. The SPE eluate was injected into a Phenomenex UHPLC Kinetex Polar C18 Column $(2.1 \times 100$ $\mathrm{mm}, 2.6 \mathrm{~mm}$ ) and detected by an Agilent 6470 triple-quadrupole mass spectrometer. All mycotoxins were separated under $6.8 \mathrm{~min}$ with electrospray ionization in multiple reaction monitoring modes. The calibration curves ranged from 0.5 to $600 \mathrm{ng} / \mathrm{mL}$ $\left(\mathrm{r}^{2}>0.99\right)$, LOQ values were between 0.25 to $10 \mathrm{ng} / \mathrm{mL}$, and LOD values were between 5 to $20 \mathrm{ng} / \mathrm{mL}$. All the QCs have shown precision, and the accuracy range for intra-day and inter-day did not exceed $14.3 \%$ (RSD) and 91.2 to $117.6 \%$ (relative error). The matrix effect and extraction recovery for five types of betel nuts were in the range of 81.5 to $99.2 \%$ and 70.1 to $113.9 \%$, respectively (except deoxynivalenol).
\end{abstract}

\section{OPEN ACCESS}

Received: May 21, 2021

Revised: July 7, 2021

Accepted: July 8, 2021

Corresponding Author:

Wei-Jun Chien

wjchien@gm.cyut.edu.tw

Copyright: The Author(s). This is an open access article distributed under the terms of the Creative Commons Attribution License (CC BY 4.0), which permits unrestricted distribution provided the original author and source are cited.

Publisher:

Chaoyang University of

Technology

ISSN: 1727-2394 (Print)

ISSN: $1727-7841$ (Online)
Keywords: LC-MS/MS, Mycotoxin, Multiple reaction monitoring (MRM).

\section{INTRODUCTION}

Although the International Agency for Cancer Research (IARC) has classified betel quid and areca nut as carcinogenic to human beings (Group 1), millions of people consume these in the Asia-Pacific region. Also, according to the World Health Organization (WHO) information, nut chewing habit increases the risk of oral cancer. In the early years, betel was regarded as a medicinal plant, which can relieve diarrhea, repel worms, and cure diseases. Since the late 1980s, the exciting and refreshing effects betel quid and areca nut have gradually become the choice snacks for Taiwanese people to refresh their work and social activities. Mycotoxins are secondary metabolites and the most common cause of poisoning and severe health risks to humans and animals by several fungi and mold. These natural toxins are often the pollutants in the food chain, causing adverse effects on human health through consumption. Different studies have demonstrated that ingested mycotoxins lead to ulcerative colitis, diarrhea, vomiting and induces DNA damage in the brain, liver, and kidneys (Freire et al., 2018). Moreover, the presence of mycotoxins in agricultural products such as cereal, nuts, cooking oil, fruit juice, and beer is a significant safety concern. Accordingly, establishing a fast analytical method to quantify mycotoxins' levels is a critical aspect of the safety evaluation of food items.

Mycotoxin contamination in commonly consumed food commodities such as dairy food, cereals, fruits, and oils is a significant cause of concern. Food processing systems 


\section{International Journal of Applied Science and Engineering}

Lin et al., International Journal of Applied Science and Engineering, 18(5), 2021145

cannot wholly remove mycotoxins (Rodríguez and Núñez, 2020). The adverse healtheffects of chewing betel nut containing mycotoxins range from long-term consequences such as immune deficiency and cancer (Lechner et al., 2019). The Food and Drug Administration (TFDA), Department of Health, Executive Yuan, Taiwan, among others, have established maximum permitted or recommended levels for several mycotoxins, including aflatoxins (AF) B1, B2, G1 and G2, ochratoxin A (OTA), deoxynivalenol (DON), zearalenone (ZEN), fumonisins (FB1 and FB2) in different food commodities (Chang et al., 2018). Various analytical methods for mycotoxins have been reported (Luo et al., 2018). ELISA (enzyme-linked immunosorbent assay) is a commonly used biochemical assay (Azri et al., 2018). Another method is LC-UV/FLD (liquid chromatography combined with fluorescence and ultraviolet) (MuñozSolano et al., 2020; Zhang et al., 2018). In recent years, high-performance liquid chromatography coupled with mass spectrometry has been the most powerful analytical instrument for qualitative and quantitative analysis of mycotoxins. Electrospray ionization (ESI) is the most popular method for ionization of molecules in liquid form and is compatible with most chromatographic separation systems (Laganà 2017; Santos Pereira et al., 2019). LC-ESIMS offers several advantages, such as improved accuracy of molecular weight and precision of reproducibility. Besides, the triple Quadrupole can be used for tandem mass spectrometry (MS/MS) to provide better selectively and higher sensitivity by MRM (multiple reaction monitoring) scan mode (Lin et al., 2020).

Current challenges are reducing significant matrix interferences from the sample extraction technique for mycotoxins and improving extraction efficiency. The SPE (solid-phase extraction) and LLE (liquid-liquid extraction) have been reported for the extraction of different mycotoxins in matrices such as body fluids (urine and blood) or common food (De Souza et al., 2013; Escrivá et al., 2017). Since the QuEChERS (quick, easy, cheap, effective, rugged, and safe) extraction method has been developed, the published method was improved to enlarge both pesticide and mycotoxins scope (Pantano et al., 2021; Sun et al., 2016; Tolosa et al., 2019). This study aimed to develop a rapid LCESI-MS/MS method and validate a simple sample extraction method for the simultaneous determination of nine mycotoxins in commercially available five types of betel nuts.

\section{EXPERIMENTAL SECTION}

\subsection{Reagents and Chemicals}

The analytical standards of mycotoxins (aflatoxins B1/B2/G1/G2, ochratoxin A, deoxynivalenol, zearalenone, and fumonisins FB1/B2) were purchased from SigmaAldrich (USA). Methanol, formic acid, acetonitrile, and other solvents, all HPLC grade, were obtained from Merck (Germany). Oasis PRiME HLB Cartridge (3 mL, $150 \mathrm{mg}$ ) was obtained from Waters (USA). Distilled water (18.2 $\mathrm{M} \Omega \cdot \mathrm{cm})$ was purified using a Sartorius arium pro (Germany).

\subsection{Samples and Sample Preparation}

Five commonly used betel nut products (shown in Fig.1) were purchased from different betel nut stores in Taichung,
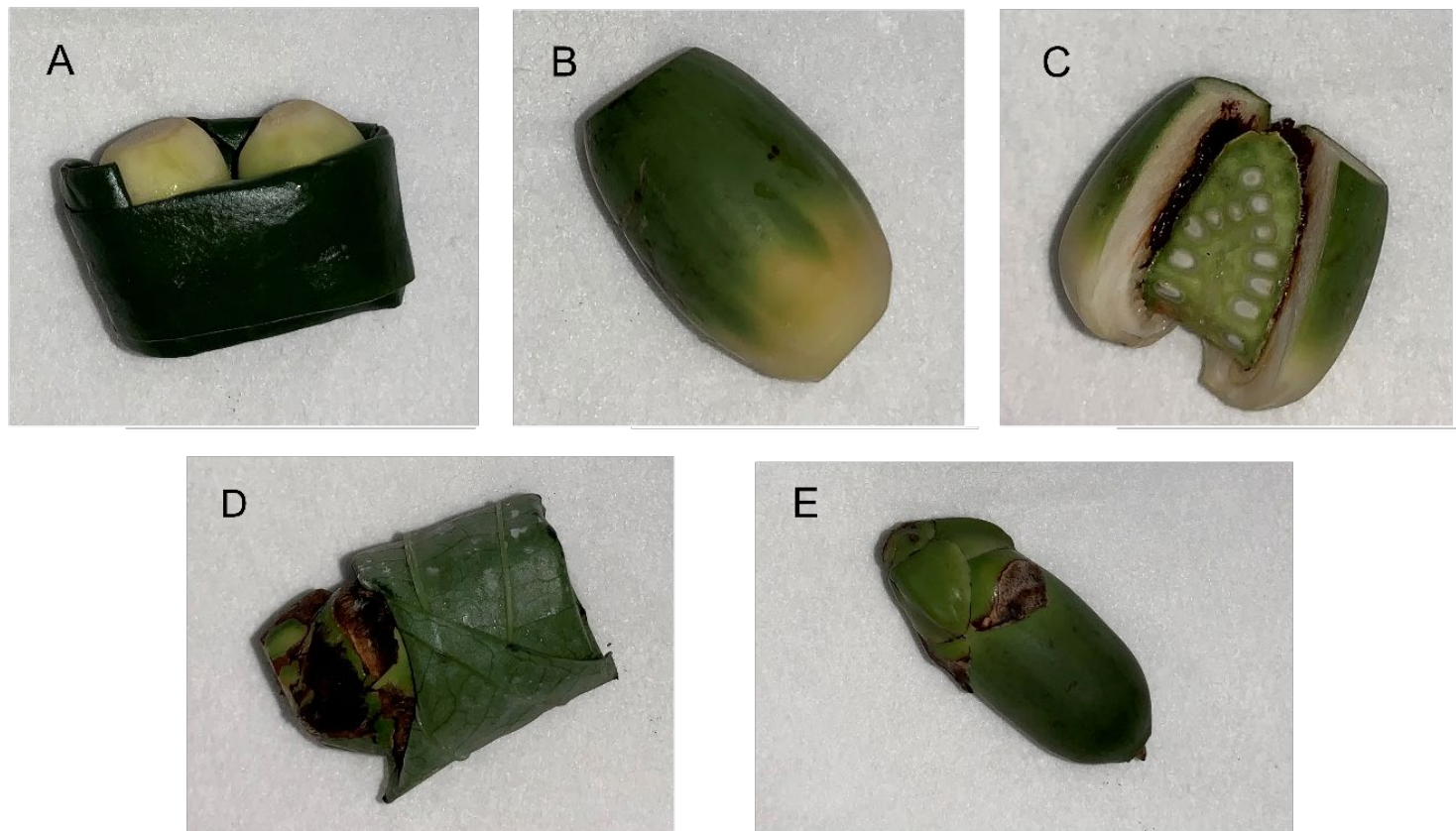

Fig. 1. Five common types of betel nut products: (A) Shuang-Zi-sing (B) Unripe areca fruit (C) Ching-a (D) Bao-hyeo and (E) Areca fruit 
Taiwan. These five betel nut products were separately pulverized into homogeneous samples by a laboratory mill for further extraction. An aliquot of a $1.0 \mathrm{~g}$ homogenized sample was weighed, and $10 \mathrm{~mL}$ of extraction solvent (acetonitrile/MeOH/water (70:10:20, v/v/v) was added to the $50 \mathrm{~mL}$ test tube. The mixture was vortexed for $3 \mathrm{~min}$ and subsequently used for ultrasonic-assisted extraction for 10 $\min$. After that, the tube was centrifuged at $3000 \mathrm{rpm}$ for 15 min at a temperature of $8^{\circ} \mathrm{C}$. Then, a $1 \mathrm{~mL}$ supernatant was passed through the Oasis PRiME HLB cartridge (MuñozSolano and González-Peñas, 2020; Zhang et al., 2016). Each cartridge was washed with $2 \mathrm{~mL}$ of $5 \%$ methanol in water, and mycotoxins were eluted with $1 \mathrm{~mL}$ of $95 \%$ methanol in water. The extract was evaporated with a nitrogen stream, and the dry extract was reconstituted with $200 \mu \mathrm{L}$ of $5 \%$ acetonitrile in water. The extract solution was sealed in a $1.5 \mathrm{~mL}$ vial and stored at $-8^{\circ} \mathrm{C}$ until analysis.

\subsection{Instruments and HPLC-MS/MS Analysis}

Analysis of mycotoxins was carried out on an Agilent HPLC-MS/MS system (Agilent Corp., USA) consisting of Agilent 1260 infinity binary HPLC coupled to an Agilent 6470 triple quadrupole mass spectrometer equipped with an ESI ionization source with Agilent Jet Stream. Chromatographic separation was performed on a UHPLC Kinetex Polar C18 Column (2.1 x $100 \mathrm{~mm}, 2.6 \mu \mathrm{m}$, Phenomenex, Torrance, CA, USA) (Fibigr et al., 2017). The chromatographic separation of the nine mycotoxins was carried out by a gradient elution program using mobile phase A (water, $0.1 \%$ formic acid) and mobile phase B (acetonitrile, $0.1 \%$ formic acid). The gradient elution program was performed as follows: 0.0 to $1.0 \mathrm{~min}, 5 \% \mathrm{~B}$; 1.1 to $7.0 \mathrm{~min}, 50$ to $85 \% \mathrm{~B} ; 7.1$ to $11.0 \mathrm{~min}, 100 \% \mathrm{~B} ; 11.1$ to $15.0 \mathrm{~min}, 5 \% \mathrm{~B}$. The HPLC flow rate was set at 0.3 $\mathrm{mL} / \mathrm{min}$, and the total runtime was $15 \mathrm{~min}$. The injection volume was $10.0 \mu \mathrm{L}$, and the column chamber and sample chamber were kept at a constant temperature of $40^{\circ} \mathrm{C}$ and $10^{\circ} \mathrm{C}$, respectively. The QqQ mass spectrometer parameters used were: capillary voltage $4.0 \mathrm{kV}$ (positive mode), nozzle $0.0 \mathrm{kV}$, sheath gas flow $11 \mathrm{~L} / \mathrm{min}$, sheath gas temperature $300^{\circ} \mathrm{C}$, nebulizer pressure $35 \mathrm{psi}$, dry gas flow $7.0 \mathrm{~L} / \mathrm{min}$ and dry gas flow temperature $350^{\circ} \mathrm{C}$. This tandem MS method used MRM scan mode by time segment, with quantifier ion (most intense transition) and qualifier ion was monitored for each mycotoxin compound. Tandem MS detection was performed using the dynamic mode to obtain at least 13 identification points. The most intense transition was used for quantification, and the other ones were used as qualifying ions. Table 1 lists the monitored ions, the MS/MS acquisition parameters used for the identification and quantification of the mycotoxins in solvent, as well as the retention time of each target analyte. The MRM parameters of all compounds, including the precursor ion $(\mathrm{m} / \mathrm{z})$, fragment ions $(\mathrm{m} / \mathrm{z})$, collision energy $(\mathrm{eV})$, dwell time $(\mathrm{ms})$, fragmentor energy (V), polarity, MRM time window ( $\mathrm{min}$ ), and retention time $(\mathrm{min})$ are shown in Table 1. Data acquisition and processing were carried out by MassHunter software (Agilent Corp., USA). Statistical analyses were performed with GraphPad Prism 8 software (GraphPad Software, USA) and Microsoft Office Excel (Microsoft Crop., USA).

\subsection{Preparation of Stock and Quality Control Samples (QCs)}

The nine standards of the mycotoxins were dissolved in water $/ \mathrm{MeOH}(95: 5 \mathrm{v} / \mathrm{v})$ as primary stock standard solutions. Serial calibration standard solutions at levels of $0.5,1.0,5.0$, $10,25,50$, and $250 \mathrm{ng} / \mathrm{mL}$ for aflatoxin B1/G1/B2/G2 and ochratoxin A; levels of 5, 10, 25, 50, 100, 200, and 400 $\mathrm{ng} / \mathrm{mL}$ for deoxynivalenol and zearalenone; levels of 20,40 , $80,100,200,300$, and $600 \mathrm{ng} / \mathrm{mL}$ for fumonisin B1/B2. Quality control samples (QCs) at levels were prepared in

Table 1. Triple quadrupole mass spectrometer detection parameters and transitions of mycotoxin

\begin{tabular}{|c|c|c|c|c|c|c|c|c|c|c|}
\hline \multirow[t]{2}{*}{ Compound } & \multirow[t]{2}{*}{ CAS number } & \multirow[t]{2}{*}{ Polarity } & RT & $\begin{array}{c}\text { Precursor } \\
\text { Ion }\end{array}$ & $\begin{array}{l}\text { Product } \\
\text { Ion }\end{array}$ & Fragmentor & $\begin{array}{c}\text { Collision } \\
\text { energy }\end{array}$ & $\begin{array}{c}\text { Accelerator } \\
\text { voltage }\end{array}$ & $\begin{array}{c}\text { dwell } \\
\text { time }\end{array}$ & $\begin{array}{c}\text { Time } \\
\text { segment }\end{array}$ \\
\hline & & & $(\min )$ & $(\mathrm{m} / \mathrm{z})$ & $(\mathrm{m} / \mathrm{z})$ & (V) & $(\mathrm{eV})$ & (V) & (ms) & $(\min )$ \\
\hline $\begin{array}{c}\text { Aflatoxin } \\
\text { B1 (AFB1) }\end{array}$ & $1162-65-8$ & Positive & 4.9 & 313 & $\begin{array}{c}241 \\
285^{*}\end{array}$ & 185 & 20 & 5 & 20 & $4.2-5.2$ \\
\hline $\begin{array}{c}\text { Aflatoxin } \\
\text { G1 (AFG1) }\end{array}$ & $1165-39-5$ & Positive & 4.6 & 329 & $\begin{array}{c}243 \\
200^{*}\end{array}$ & 185 & 25 & 5 & 20 & $4.2-5.2$ \\
\hline $\begin{array}{c}\text { Aflatoxin } \\
\text { B2 (AFB2) }\end{array}$ & $7220-81-7$ & Positive & 4.8 & 315 & $\begin{array}{c}287 \\
259 *\end{array}$ & 185 & 25 & 5 & 20 & $4.2-5.2$ \\
\hline $\begin{array}{c}\text { Aflatoxin } \\
\text { G2 (AFG2) }\end{array}$ & $7241-98-7$ & Positive & 4.4 & 331 & $\begin{array}{c}245 \\
189 *\end{array}$ & 185 & 25 & 5 & 150 & $4.2-5.2$ \\
\hline $\begin{array}{c}\text { Ochratoxin } \\
\text { A (OTA) }\end{array}$ & $303-47-9$ & Positive & 6.8 & 404 & $\begin{array}{c}239 \\
102 *\end{array}$ & 140 & 24 & 5 & 70 & $6.4-7.4$ \\
\hline $\begin{array}{l}\text { Deoxynivalenol } \\
\text { (DON) }\end{array}$ & $51481-10-8$ & Positive & 3.5 & 297 & $\begin{array}{c}249 \\
203^{*}\end{array}$ & 115 & 20 & 5 & 200 & $3.3-3.9$ \\
\hline $\begin{array}{c}\text { Zearalenone } \\
(\text { ZEN })\end{array}$ & $17924-92-4$ & Positive & 6.6 & 319 & $\begin{array}{c}283 \\
185^{*}\end{array}$ & 115 & 24 & 5 & 120 & $6.4-7.4$ \\
\hline $\begin{array}{c}\text { Fumonisin } \\
\text { B1 (FB1) }\end{array}$ & $116355-83-0$ & Positive & 5.6 & 722 & $\begin{array}{c}334 \\
352 *\end{array}$ & 185 & 30 & 5 & 200 & $5.4-5.9$ \\
\hline $\begin{array}{l}\text { Fumonisin } \\
\text { B2 (FB2) }\end{array}$ & $116355-84-1$ & Positive & 6.7 & 706 & $\begin{array}{c}336 \\
318^{*}\end{array}$ & 185 & 30 & 5 & 20 & $6.4-7.4$ \\
\hline
\end{tabular}

${ }^{*}$ Qualitative ion of an analyte. 
each mycotoxin at QC-low, QC-mid and QC-high concentrations: aflatoxins B1/G1/B2/G2 and ochratoxin A $(0.5,50$, and $250 \mathrm{ng} / \mathrm{mL})$, deoxynivalenol and zearalenone $(5,50$, and $400 \mathrm{ng} / \mathrm{mL})$, fumonisins B1/B2 $(20,200$, and 600 $\mathrm{ng} / \mathrm{mL})$. The stock solutions and QCs were stored at $-20^{\circ} \mathrm{C}$ in amber glass vials before use.

\subsection{Validation Parameters}

The Food and Drug Administration (TFDA) provides guidelines for bioanalytical method validation. These aspects include linearity, sensitivity, precision, accuracy, extraction efficiency, recovery, and matrix effect validated in MRM scan mode. The sensitivity of the method was determined by signal-to-noise ratios $(\mathrm{S} / \mathrm{N})>3$ for quantifying the limit of detection (LOD) and signal-to-noise ratios $(\mathrm{S} / \mathrm{N})>10$ for the limit of quantification (LOQ). The validation of the sensitivity, including the LOQ, is based on empirical investigations of analyte concentrations from 0.5 to $20 \mathrm{ng} / \mathrm{mL}$. The precision and accuracy were evaluated by a QC-low, QC-mid, and QC-high concentration level, three independent runs in one day and three consecutive days. The results of precision were expressed as the relative standard deviations (RSD) of the peak areas. The intra- and inter-day precisions were required to be $<15 \%$ ( $\leq 20 \%$ for the lower limit of quantification). The accuracy was calculated by dividing the found QCs by the nominal linearity calibration curves point; the assay accuracy was expressed as the relative error ( 85 to $115 \%$, and 80 to $120 \%$ for the lower limit of quantification). The matrix effect and extraction recovery were determined at LOQ and ten times LOQ levels in five common types of betel nut products. Matrix effect was evaluated by dividing the peak area of the spiked concentrations at post-extracted to the spiked concentrations at the neat solution and multiplied by $100 \%$. The extraction recovery was calculated by dividing the spiked concentrations at pre-extracted before SPE by spiked concentrations at post-extracted and multiplied by $100 \%$.

\section{RESULTS AND DISCUSSION}

\subsection{Optimization of HPLC-MS/MS Conditions}

The $\mathrm{C} 18$ stationary phase is a suitable model for the use of reversed-phase chromatography. However, polar compounds in higher aqueous phase conditions enhance the selectivity and related peak shape issues. For example, to prevent the traditional C18 stationary phase from phase collapse under $100 \%$ aqueous conditions and reduce the compound's shift of retention. However, the surface of the UHPLC Kinetex Polar C18 Column can provides polar and non-polar retention alongside $100 \%$ aqueous stability (Desmarchelier et al., 2020). The optimization of MRM parameters for multi-mycotoxins was optimized with the
Agilent MassHunter Optimizer program to determine the two transitions (Quan/Qual ion) for each analyte. This MRM method designed a time segments method (the divert valve to waste or MS) to reduce the chance of instrument contamination. Meanwhile, the chromatography conditions were optimized to ensure each compound dwell time for all transitions gives an appropriate cycle time. Different types of mobile phase (acetonitrile and methanol) were estimated, including additives (formic acid, ammonium format, and ammonium acetate) were observed to give a lower bake pressure, better peak shape, and faster time compared to acetonitrile with $0.1 \%$ formic acid (data non shown) (Gai et al., 2020). According to the conditions of each mycotoxin hydrophilic and hydrophobic effect, a single run within 15 min (Fig. 2) was chosen to optimize HPLC and MS parameters.

\subsection{Sensitivity and Linearity}

The LOD and LOQ are respectively defined as the lowest detectable amount $(\mathrm{S} / \mathrm{N}$ ratio $>3)$ and limit of quantitation $(\mathrm{S} / \mathrm{N}$ ratio $>10)$. More specifically, the method sensitivity is defined by the LOD and LOQ. In this experiment, the LODs have not used matrix matching; hence diluting half of the LOQ is a relatively stable strategy. The LLOQ was used as the lowest calibration point for each mycotoxin $(0.5 \mathrm{ng} / \mathrm{mL}$ for ochratoxin A and aflatoxin B1/G1/B2/G2; $20 \mathrm{ng} / \mathrm{mL}$ for fumonisin $\mathrm{B} 1 / \mathrm{B} 2 ; 5 \mathrm{ng} / \mathrm{mL}$ for deoxynivalenol and zearalenone). Calibration curves were linear within the concentration ranges ( 0.5 to $600 \mathrm{ppb})$ and dependent on each mycotoxin. The linear regression correlation coefficients $\left(\mathrm{r}^{2}\right)$ were at least 0.99 in all validation runs (Table 2). The linearity was evaluated based on seven-point calibration curves. These results showed that the method developed in the study has good sensitivity and has an excellent linear range for quantification (Zhang et al. 2018).

\subsection{Precision and Accuracy}

Precision and accuracy were determined by measuring the QCs (QC-low, QC-mid, and QC-high), respectively. Intra-day precision and accuracy were assessed by injecting three replicates of each QCs on the same day. Inter-day precision and accuracy were determined by injecting three replicates of each QCs every day over three days. The validation results of the inter-day and intra-day for precision and accuracy are shown in Table 2. For the precision and accuracy determination; the RSD\% values of intra-day and inter-day ranged from $1.1 \%$ to $14.3 \%$; The RE\% values was within 91.2 to $117.6 \%$. None of the RSD and RE values of the nine analytes exceeded $15 \%$ and 80 to $120 \%$, respectively. These results proved that the method had excellent precision, accuracy, and stability on an intra- or inter-day basis. 
Lin et al., International Journal of Applied Science and Engineering, 18(5), 2021145

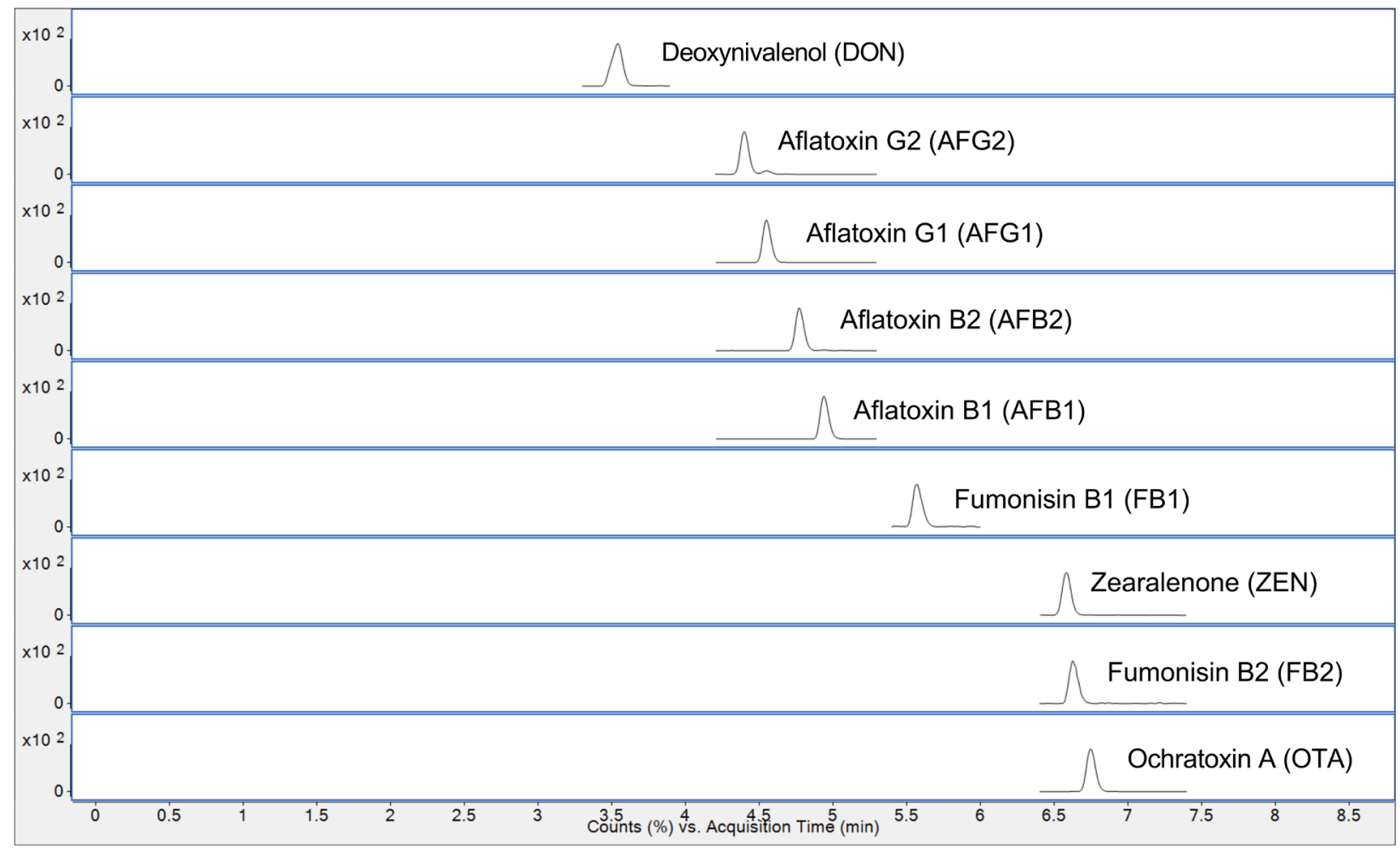

Fig. 2. HPLC-MS/MS MRM chromatograms of nine multi-mycotoxins standard solutions

\subsection{Extraction Recovery and Matrix Effect}

The response ratios of matrix effect (ME) lower or higher than $100 \%$ indicate signal suppression or enhancement. The extraction recovery (ER) explores whether the loss in the purification process can be accepted. The results shown in Table 3, based on two spiked LOQ and ten times LOQ concentration levels for each mycotoxin ( 0.5 to 200.0 $\mathrm{ng} / \mathrm{mL}$ ), in five types of betel nuts compared to equal levels in the solvent, shows promising results (ER: 70.1 to 113.9; ME: 80.2 to 99.2). These results confirm that the deoxynivalenol (DON) not effectively reduced the matrix suppression effects and higher recovery with LC gradient elution schemes in betel nuts (Ałtyn and Twarużek, 2020; Bryła et al., 2018; Geng et al., 2014).

\subsection{Real Samples Analysis}

This method considers a new UHPLC Kinetex Polar C18 column for HPLC-MS analysis of nine mycotoxins in MRM scanning mode while optimizing the product ion $(\mathrm{m} / \mathrm{z})$, fragmentor, collision energy $(\mathrm{eV})$, accelerator voltage $(\mathrm{V})$, polarity and time segment ( $\mathrm{min})$ of the respective standards. In addition, this method provided a fast determination of multi-mycotoxins around $7 \mathrm{~min}$ and possible to avoid the co-elution of some mycotoxins for respective retention time. Eventually, this newly developed method has been used to analyze five products in local betel nut stores, including Shuang-Zi-sing, unripe areca fruit, Ching-a, Bao-hyeo, and Areca fruit. Furthermore, all mycotoxins in 5 betel samples were not detected by the HPLC-MS/MS, and the signals were lower than their respective LOQs. Although no artificial moldy control samples can be tested in this study, that method of detection limit did not exceed the LOQs set by the Food and Drug Administration (TFDA), Taiwan (Liao et al., 2013).

\section{CONCLUSION}

A feasible SPE-LC-MS/MS method was developed and fully validated for the nine simultaneous determinations of mycotoxin in the betel. All accuracy and precision were evaluated by the intra- and the inter-day, which expressed the repeatability and reliability in this method. Except for Deoxynivalenol (DON), both the recovery rate and matrix effect are acceptable in this validation. The reason may be that the SPE column cannot effectively react with the stationary phase. The value is too low, which also shows the importance of the immunoaffinity purification method. Detection limit and quantification limits obtained using LCMS/MS did not exceed within the Food and Drug Administration (TFDA), Taiwan. Meanwhile, there have been few studies on the detection of mycotoxins in betel nut by LC-MS (Liu et al., 2016). The results of this study can thus provide betel products to promote the risk evaluation of food safety.

\section{ACKNOWLEDGEMENTS}

This work was financially supported by the Green Center 


\section{International Journal of Applied Science and Engineering}

Lin et al., International Journal of Applied Science and Engineering, 18(5), 2021145

Table 2. Linearity, LOD, LOQ, precision, and accuracy for determination of nine mycotoxins in quality control samples

\begin{tabular}{|c|c|c|c|c|c|c|c|c|c|}
\hline \multirow{2}{*}{ Mycotoxin } & \multirow{2}{*}{$\begin{array}{c}\text { Regression } \\
\left(\mathrm{r}^{2}\right)\end{array}$} & \multirow{2}{*}{$\frac{\text { Linear range }}{(\mathrm{ng} / \mathrm{mL})}$} & \multirow{2}{*}{$\frac{\text { LOD }}{(\mathrm{ng} / \mathrm{mL})}$} & \multirow{2}{*}{$\frac{\mathrm{LOQ}}{(\mathrm{ng} / \mathrm{mL})}$} & \multirow{2}{*}{$\frac{\text { QCs }}{\text { Conc. }(\mathrm{ng} / \mathrm{mL})}$} & \multicolumn{2}{|c|}{ Intra-day $(n=3)$} & \multicolumn{2}{|c|}{ Inter-day $(\mathrm{n}=3)$} \\
\hline & & & & & & $\operatorname{RSD}(\%)$ & Accuracy $(\%)$ & RSD (\%) & Accuracy $(\%)$ \\
\hline $\begin{array}{l}\text { Aflatoxin } B_{1} \\
\text { (AFB1) }\end{array}$ & 0.997 & $0.5-100$ & 0.25 & 0.5 & 40 & 2.4 & 95.6 & 5.5 & 117.6 \\
\hline \multirow{2}{*}{$\begin{array}{l}\text { Aflatoxin } \mathrm{G}_{1} \\
\quad(\mathrm{AFG} 1)\end{array}$} & \multirow[b]{2}{*}{0.991} & \multirow[b]{2}{*}{$0.5-100$} & \multirow[b]{2}{*}{0.25} & \multirow[b]{2}{*}{0.5} & 0.5 & 8.1 & 91.9 & 8.7 & 102.7 \\
\hline & & & & & 40 & 2.1 & 104.2 & 5.6 & 104.9 \\
\hline \multirow{2}{*}{$\begin{array}{l}\text { Aflatoxin } B_{2} \\
\quad(\text { AFB2) }\end{array}$} & \multirow[t]{2}{*}{0.998} & \multirow[t]{2}{*}{$0.5-100$} & \multirow[t]{2}{*}{0.25} & \multirow[t]{2}{*}{0.5} & 40 & 1.1 & 110.1 & 9.7 & 102.5 \\
\hline & & & & & 100 & 6.3 & 98.9 & 9.9 & 100.7 \\
\hline \multirow{3}{*}{$\begin{array}{l}\text { Aflatoxin } G_{2} \\
\quad(\text { AFG2) }\end{array}$} & \multirow{3}{*}{0.993} & \multirow{3}{*}{$0.5-100$} & \multirow{3}{*}{0.25} & \multirow{3}{*}{0.5} & 0.5 & 11.4 & 107.6 & 14.1 & 99.6 \\
\hline & & & & & 40 & 9.0 & 102.6 & 5.9 & 95.3 \\
\hline & & & & & 100 & 2.9 & 99.0 & 3.7 & 97.5 \\
\hline $\begin{array}{l}\text { Deoxynivalenor } \\
\text { (DON) }\end{array}$ & 0.990 & $5.0-200$ & 2.5 & 5.0 & 50 & 9.5 & 100.2 & 8.8 & 97.0 \\
\hline & & & & & 200 & 4.3 & 103.2 & 7.3 & 107.2 \\
\hline & & & & & 5.0 & 12.2 & 113.4 & 14.0 & 106.5 \\
\hline $\begin{array}{l}\text { Zearalenone } \\
\text { (ZEN) }\end{array}$ & 0.992 & $5.0-200$ & 2.5 & 5.0 & 50 & 11.2 & 100.6 & 5.7 & 104.3 \\
\hline & & & & & 200 & 9.9 & 99.6 & 13.5 & 99.5 \\
\hline & & & & & 20 & 11.4 & 97.6 & 13.5 & 95.6 \\
\hline (FB1) & 0.994 & $20-500$ & 10 & 20.0 & 160 & 2.5 & 102.4 & 9.3 & 91.2 \\
\hline & & & & & 500 & 1.4 & 113.6 & 7.5 & 100.6 \\
\hline & & & & & 20 & 13.5 & 98.1 & 12.8 & 96.3 \\
\hline (FB2) & 0.991 & $20-500$ & 10 & 20.0 & 160 & 5.4 & 114.6 & 8.7 & 100.5 \\
\hline
\end{tabular}

Table 3. Matrix effect and extraction recovery at two spiked concentration levels for studied mycotoxin in five types of betel nut

\begin{tabular}{|c|c|c|c|c|c|c|c|c|c|c|c|}
\hline \multirow[t]{2}{*}{ Mycotoxin } & \multirow[t]{2}{*}{ spiked cone. } & \multicolumn{5}{|c|}{ Matrix effects $(\%) n=3$} & \multicolumn{5}{|c|}{ Extraction recovery $(\%) n=3$} \\
\hline & & $\begin{array}{l}\text { Shuang- } \\
\text { Zi-sing }\end{array}$ & $\begin{array}{c}\text { Unripe } \\
\text { areca fruit }\end{array}$ & $\begin{array}{c}\text { Ching } \\
-\mathrm{a}\end{array}$ & $\begin{array}{l}\text { Bao- } \\
\text { hyeo }\end{array}$ & $\begin{array}{l}\text { Areca } \\
\text { fruit }\end{array}$ & $\begin{array}{l}\text { Shuang- } \\
\text { zi-sing }\end{array}$ & $\begin{array}{c}\text { Unripe } \\
\text { areca fruit }\end{array}$ & $\begin{array}{c}\text { Ching } \\
-\mathrm{a}\end{array}$ & $\begin{array}{l}\text { Bao- } \\
\text { hyeo }\end{array}$ & $\begin{array}{l}\text { Areca } \\
\text { fruit }\end{array}$ \\
\hline \multirow{2}{*}{$\begin{array}{l}\text { Aflatoxin B1 } \\
\text { (AFB1) }\end{array}$} & LOQ & 89.3 & 89.4 & 98.2 & 98.1 & 98.3 & 74.5 & 72.3 & 80.2 & 78.2 & 109.6 \\
\hline & 10x LOQ & 88.9 & 93.1 & 90.3 & 83.4 & 97.1 & 89.5 & 76.2 & 70.9 & 74.5 & 113.9 \\
\hline Aflatoxin & LOQ & 95.3 & 98.9 & 89.1 & 87.6 & 91.5 & 79.9 & 77.7 & 106.5 & 84.2 & 110.5 \\
\hline G1(AFG1) & 10x LOQ & 89.4 & 81.3 & 84.3 & 78.1 & 90.5 & 85.6 & 78.5 & 107.5 & 90.5 & 102.8 \\
\hline \multirow{2}{*}{$\begin{array}{c}\text { Aflatoxin B2 } \\
\text { (AFB2) }\end{array}$} & LOQ & 87.2 & 91.1 & 81.5 & 89.6 & 96.5 & 89.6 & 71.5 & 78.5 & 79.9 & 98.5 \\
\hline & 10x LOQ & 88.1 & 85.3 & 88.1 & 95.3 & 93.7 & 84.1 & 86.4 & 88.6 & 95.2 & 96.5 \\
\hline \multirow{2}{*}{$\begin{array}{l}\text { Aflatoxin G2 } \\
\text { (AFG2) }\end{array}$} & LOQ & 95.6 & 84.1 & 98.4 & 95.5 & 94.3 & 85.6 & 80.9 & 81.3 & 70.5 & 101.1 \\
\hline & 10x LOQ & 94.2 & 84.9 & 80.3 & 97.3 & 92.5 & 88.8 & 84.1 & 88.9 & 96.4 & 98.6 \\
\hline \multirow{2}{*}{$\begin{array}{l}\text { Ochratoxin A } \\
\text { (OTA) }\end{array}$} & LOQ & 95.3 & 87.3 & 90.8 & 78.2 & 88.2 & 78.9 & 82.2 & 89.3 & 108.6 & 100.2 \\
\hline & 10x LOQ & 96.2 & 98.3 & 81.4 & 94.2 & 92.4 & 71.6 & 85.2 & 74.1 & 89.6 & 103.1 \\
\hline \multirow{2}{*}{$\begin{array}{c}\text { Deoxynivalenol } \\
\text { (DON) }\end{array}$} & LOQ & 32.1 & 44.5 & 62.3 & 60.2 & 50.2 & 41.9 & 52.3 & 48.3 & 49.8 & 25.1 \\
\hline & 10x LOQ & 25.8 & 39.4 & 28.6 & 49.5 & 33.3 & 40.3 & 32.9 & 22.6 & 66.7 & 37.1 \\
\hline \multirow{2}{*}{$\begin{array}{l}\text { Zearalenone } \\
(\text { ZEN })\end{array}$} & LOQ & 91.4 & 96.2 & 87.4 & 80.4 & 89.6 & 85.2 & 70.1 & 74.2 & 77.5 & 102.9 \\
\hline & 10x LOQ & 94.6 & 90.5 & 90.9 & 85.2 & 99.2 & 80.6 & 78.2 & 79.5 & 77.2 & 98.5 \\
\hline \multirow{4}{*}{$\begin{array}{l}\text { Fumonisin B1 } \\
\text { (FB1) } \\
\text { Fumonisin B2 } \\
(\text { FB2 })\end{array}$} & LOQ & 98.3 & 92.1 & 82.1 & 87.1 & 86.3 & 79.6 & 79.1 & 80.3 & 97.2 & 100.1 \\
\hline & 10x LOQ & 97.5 & 93.6 & 99.9 & 92.1 & 85.1 & 89.1 & 75.5 & 70.5 & 98.7 & 97.3 \\
\hline & LOQ & 81.5 & 89.3 & 80.2 & 90.3 & 96.5 & 79.5 & 89.6 & 75.1 & 70.6 & 95.4 \\
\hline & 10x LOQ & 83.9 & 81.9 & 88.8 & 84.2 & 98.5 & 86.1 & 85.6 & 76.5 & 70.8 & 94.5 \\
\hline
\end{tabular}


of Agriculture by the Chaoyang University of Technology, Taichung, Taiwan (R.O.C). The authors declare no financial or commercial conflict of interest among them.

\section{REFERENCES}

Ałtyn, I., Twarużek, M. 2020. Mycotoxin contamination concerns of herbs and medicinal plants. Toxins, 12, 182195.

Azri, F.A., Sukor, R., Selamat, J., Abu Bakar, F., Yusof, N.A., Hajian, R. 2018. Electrochemical immunosensor for detection of aflatoxin $\mathrm{B} 1$ based on indirect competitive ELISA. Toxins, 10, 196-209.

Bryła, M., Ksieniewicz-Woźniak, E., Waśkiewicz, A., Szymczyk, K., Jędrzejczak, R. 2018. Natural occurrence of nivalenol, deoxynivalenol, and deoxynivalenol-3glucoside in polish winter wheat. Toxins, 10, 81-93.

Chang, C.C., Kao, T.H., Zhang, D., Wang, Z., Inbaraj, B.S., Hsu, K.Y., Chen, B.H. 2018. Application of QuEChERS coupled with HPLC-DAD-ESI-MS/MS for determination of heterocyclic amines in commercial meat products. Food Analytical Methods, 11, 3243-3256.

De Souza, G.D., Mithöfer, A., Daolio, C., Schneider, B., Rodrigues-Filho, E. 2013. Identification of alternaria alternata mycotoxins by LC-SPE-NMR and their cytotoxic effects to soybean (Glycine max) cell suspension culture. Molecules, 18, 2528-2538.

Desmarchelier, A., Hamel, J., Delatour, T. 2020. Sources of overestimation in the analysis of acrylamide-in coffee by liquid chromatography mass spectrometry. Journal of Chromatography A, 1610, 460566.

Escrivá, L., Font, G., Manyes, L., Berrada, H. 2017. Studies on the presence of mycotoxins in biological samples: An overview. Toxins, 9, 251-284.

Fibigr, J., Šatínský, D., Solich, P. 2017. A UHPLC method for the rapid separation and quantification of anthocyanins in acai berry and dry blueberry extracts. Journal of Pharmaceutical and Biomedical Analysis, 143, 204-213.

Freire, L., Sant'Ana, A.S. 2018. Modified mycotoxins: An updated review on their formation, detection, occurrence, and toxic effects. Food and Chemical Toxicology, 111, 189-205.

Gai, Q.Y., Jiao, J., Wang, X., Liu, J., Fu, Y.J., Lu, Y., Wang, Z.Y., Xu, X.J. 2020. Simultaneous determination of taxoids and flavonoids in twigs and leaves of three Taxus species by UHPLC-MS/MS. Journal of Pharmaceutical and Biomedical Analysis, 189, 113456.

Geng, Z., Yang, D., Zhou, M., Zhang, P., Wang, D., Liu, F., Zhu, Y., Zhang, M. 2014. Determination of deoxynivalenol-3-glucoside in cereals by hydrophilic interaction chromatography with ultraviolet detection. Food Analytical Methods, 7, 1139-1146.

Laganà, A. 2017. Introduction to the toxins special issue on LC-MS/MS methods for mycotoxin analysis. Toxins, 9, 325-328.
Lechner, M., Breeze, C.E., Vaz, F., Lund, V.J., Kotecha, B. 2019. Betel nut chewing in high-income countries-lack of awareness and regulation. The Lancet Oncology, 20, 181-183.

Liao, C.D., Wong, J.W., Zhang, K., Hayward, D.G., Lee, N.S., Trucksess, M.W. 2013. Multi-mycotoxin analysis of finished grain and nut products using high-performance liquid chromatography-triple-quadrupole mass spectrometry. Journal of Agricultural and Food Chemistry, 61, 4771-4782.

Lin, H.Y., Liang, X.T., Yang, W.G., Chien, W.J. 2020. Highperformance liquid chromatography-tandem mass spectrometry with polar C18 for rapid quantification of anthocyanin and flavonoid in black soybean extracts. International Journal of Applied Science and Engineering, 17, 363-371.

Liu, H., Luo, J., Kong, W., Liu, Q., Hu, Y., Yang, M. 2016. UFLC-ESI-MS/MS analysis of multiple mycotoxins in medicinal and edible Areca catechu. Chemosphere, 150, 176-183.

Luo, Y., Liu, X., Li, J. 2018. Updating techniques on controlling mycotoxins-A review. Food control, 89, 123132.

Muñoz-Solano, B., González-Peñas, E. 2020. Mycotoxin determination in animal feed: An LC-FLD method for simultaneous quantification of aflatoxins, Ochratoxins and Zearelanone in This Matrix. Toxins, 12, 374-390.

Pantano, L., La Scala, L., Olibrio, F., Galluzzo, F.G., Bongiorno, C., Buscemi, M.D., Macaluso, A., Vella, A. 2021. QuEChERS LC-MS/MS screening method for mycotoxin detection in cereal products and spices. International Journal of Environmental Research and Public Health, 18, 3774-3791.

Rodríguez, M., Núñez, F. 2020. Novel approaches to minimizing mycotoxin contamination. Toxins, 12, 216219.

Santos Pereira, C.C., Cunha, S., Fernandes, J.O. 2019. Prevalent mycotoxins in animal feed: Occurrence and analytical methods. Toxins, 11, 290-352.

Sun, J., Li, W., Zhang, Y., Hu, X., Wu, L., Wang, B. 2016. QuEChERS purification combined with ultrahighperformance liquid chromatography tandem mass spectrometry for simultaneous quantification of 25 mycotoxins in cereals. Toxins, 8, 375-393.

Tolosa, J., Barba, F.J., Font, G., Ferrer, E. 2019. Mycotoxin incidence in some fish products: QuEChERS methodology and liquid chromatography linear ion trap tandem mass spectrometry approach. Molecules, 24, 527-538.

Zhang, L., Dou, X.W., Zhang, C., Logrieco, A.F., Yang, M.H. 2018. A review of current methods for analysis of mycotoxins in herbal medicines. Toxins, 10, 65-104.

Zhang, S., Zhao, Y., Li, H., Zhou, S., Chen, D., Zhang, Y., Yao, Q., Sun, C. 2016. A simple and high-throughput analysis of amatoxins and phallotoxins in human plasma, Serum and urine using UPLC-MS/MS combined with PRiME HLB $\mu$ Elution platform. Toxins, 8, 128-141. 